\title{
Unprocessed Bran in Treatment of Diverticular Disease of the Colon
}

\author{
NEIL S. PAINTER, ANTHONY Z. ALMEIDA, KENNETH W. COLEBOURNE
}

British Medical fournal, 1972, 2, 137-140

\section{Summary}

Seventy patients with diverticular disease of the colon were treated with a high-residue, low-sugar diet including unprocessed bran. Follow-up for an average of 22 months showed marked relief of symptoms in 62 patients. Bowel habit was restored towards normal and abdominal discomfort relieved. Only seven patients were unable to give up the use of laxatives. Eight patients did not tolerate the bran diet, and one of these needed surgical treatment. None of the 62 patients who took the diet needed surgery.

\section{Introduction}

Diverticular disease of the colon was regarded as a curiosity until the turn of the century. It then became a clinical problem and has since increased in incidence to become the commonest affliction of the colon in Western nations. Painter (1970) and Painter and Burkitt (1971) believe that the disease is caused by the reduction of the amount of cellulose fibre in the diet owing to the refining of carbohydrates. Historical and epidemiological studies show that diverticulosis appears in communities who change their traditional eating habits and afflicts them after they have eaten refined carbohydrates for about 40 years. A deficiency of dietary fibre alters the consistency of the faecal stream so that the sigmoid has to segment more vigorously to propel viscous faeces, and so it generates high pressures which cause the herniation of the colonic mucosa (Painter, 1964; Painter and Burkitt, 1971).

Thus diverticular disease is caused by the low-residue diet that has been recommended for its treatment for nearly 50 years despite the lack of any convincing evidence of its beneficial effect. By contrast this paper shows that in 70 patients with diverticular disease the addition of fibre in the form of unprocessed bran alleviated or abolished the symptoms of the condition provided that no structural change had caused stenosis of the colon.

Ideally, a high-residue diet, or more correctly an unrefined diet, should include plenty of fresh fruit, vegetables, and, most important of all, wholemeal bread and flour; our ancestors, who did not get diverticulosis, ate this bread in quantity and consumed much less refined sugar (Fig. 1). Unfortunately most people's diet depends on the availability of food at a price they can afford. In particular, retired people on a fixed income can often afford only cheap, processed foods. The cheapest way of adding cellulose fibre to the diet is to eat unprocessed bran. Wheat bran has a laxative effect related to the amount ingested (Cowgill and Anderson, 1932). It resists digestion by absorbing water and keeps the faeces soft, and its laxative effect exceeds that of fibre derived from fruit and vegetables (Dimock, 1936). Bran constitutes about $14.5 \%$ of the kernel and contains $12.25 \%$ fibre, which is about five times that of the whole wheat. The safety of All-Bran in the treatment of constipation has long been established, and its value was shown by Dimock (1936),

Manor House Hospital, London NW11 7 HX

who used it to treat constipation, mucous colitis, and spastic colon. Cleave (1941; personal communication, 1967) used unprocessed bran to relieve constipation both ashore and afloat in the Royal Navy and did so without any complications. Hence it seemed safe to give unprocessed bran to patients with diverticular disease.

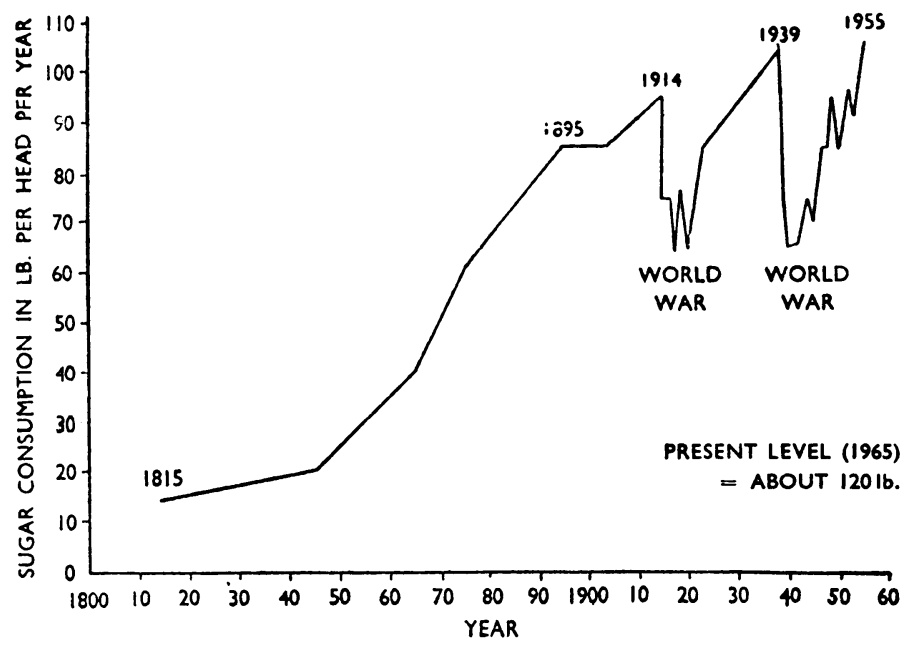

FIG. 1-Rise in sugar consumption in the U.K. from 1815 to 1955 . (From Cleave, Campbell, and Painter, 1969.)

\section{Patients and Methods}

Seventy unselected patients with diverticular disease in whom barium studies had shown no organic stenosis were placed on a high-residue, low-sugar diet together with unprocessed bran. The trial was not controlled for we believe that fibre deficiency causes diverticulosis and hence it would have been unethical for us to have given a low-residue diet ( $R$. Doll, personal communication, 1971). Patients whose symptoms suggested the presence of other diseases were investigated appropriately, but as soon as diverticula were found the patient was told of their presence. The effects of the condition were explained to them with the aid of a simple diagram and they were put on what for the sake of brevity was called the bran diet.

Each patient received from the dispensary a sheet of instructions. This explained that as unprocessed bran is difficult to swallow it should be washed down with water, milk, or fruit juice, sprinkled on cereals, or taken in soup. Patients were advised to eat All-Bran, Weetabix, porridge, wholemeal (not brown) bread, fruit, and vegetables and were told to reduce their intake of refined sugar whether it was brown or white. They were also told to take 2 teaspoons of the unprocessed bran three times a day and that after two weeks they must increase this dose if necessary until their bowels were open once or twice a day without straining. They were warned that they might suffer from flatulence but that it would be temporary. The correct dosage of bran was found by trial and error. Those who did not tolerate bran or who were not improved by it were advised to take a high-residue diet supplemented by sterculia (Normacol).

The bran trial started in.December 1967. In 1971 a questionnaire was sent to each of the 70 patients asking about the effects of the bran diet. Nearly half were interviewed. 


\section{Results}

Of the 70 patients in the trial 45 were men aged 37 to 82 (average $60 \cdot 1$ ) years, and 25 were women aged 36 to 78 (average 59.6) years. (Many more men than women attend Manor House Hospital.) Sixty-two of them took unprocessed bran regularly with benefit but eight did not do so for the reasons given below. The distribution of diverticula in the colon is given in Table I. Unpro-

TABLE I-Distribution of Colonic Diverticula Among the 70 Patients

Sigmoid colon only

Sigmoid and descending colon $\quad \ldots \quad 31$

Sigmoid, descending, and transverse

colon

Sigmoid, descending, and ascending

colon

24
3
2

Ascending and descending colon Descending colon only Transverse colon only . Ascending colon

cessed bran had been taken for three years and three months by those who entered the trial in December 1967. All 62 patients had taken the bran for at least five months by March 1971. On average the patients had eaten bran for 22 months.

\section{AMOUNT OF UNPROCESSED BRAN REQUIRED}

The amount of bran needed to prevent straining at stool varied greatly. This is probably because the amount of fibre in the rest of each patient's diet, and hence its degree of fibre depletion, varied considerably. The amount of bran required ranged from 1 dessertspoon daily ( $3 \mathrm{~g}$ ) to 3 tablespoons thrice daily ( $45 \mathrm{~g}$ ). On average 2 teaspoons three times a day (about 12 to $14 \mathrm{~g}$ ) rendered the stools soft and easy to pass. Unprocessed bran is difficult to eat dry, and so 34 patients sprinkled it on cereal, 18 took it with milk or water, eight mixed it with porridge, and two added it to soup. No fewer than 39 of the patients felt distended and suffered from flatulence when they first took unprocessed bran. Flatulence disappeared within three weeks but sometimes lasted for eight weeks. It is essential that patients are warned that bran may cause flatulence and distension and that they must not stop taking bran on this account. In three patients a sensation of slight distension persisted, but they preferred this to their previous symptoms.

\section{FAILURES}

Eight patients did not take bran. Three of them felt nauseated or distended by it; one was made comfortable with sterculia but the other two, one of whom had a history of mental disorder, sought advice elsewhere. A fourth patient preferred sterculia to bran. A further patient, who had taken senna for over 15 years, came to surgery and it was found that the myenteric plexus of his sigmoid colon had been destroyed. His symptoms were less severe but were not abolished by the combination of surgery, salts, bran, sterculia, and a high-residue diet.

The other three patients were so improved by eating wholemeal bread, All-Bran, and Weetabix that they stopped taking unprocessed bran. Thus three of the eight who did not take bran were made comfortable by the addition of cereal fibre to their diet and two were relieved by sterculia.

\section{BOWEL HABIT}

The bowel habit of the 62 patients before and after taking the bran diet is shown in Fig. 2. Not only did constipated patients pass soft motions regularly but those who formerly passed frequent small stools or had attacks of diarrhoea had fewer but soft-formed motions. Besides changing the bowel habit the bran diet altered the consistency of the stools. Before bran 45 strained at stool, nine did so sometimes, and only eight defecated without effort. After bran 51 said straining at stool was a

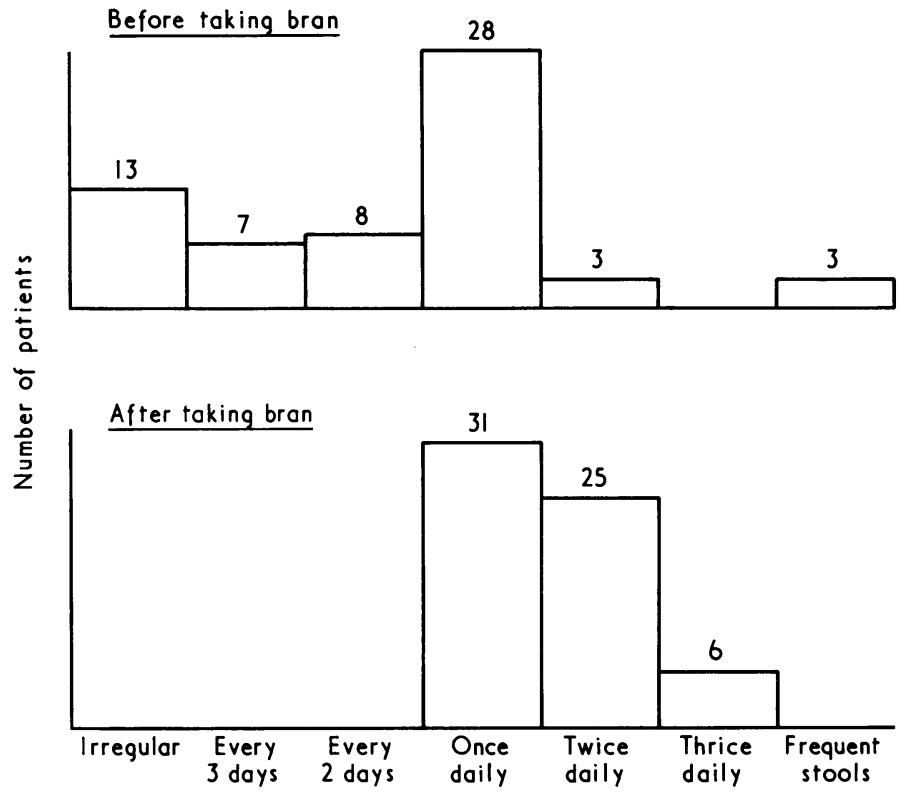

FIG. 2-Bowel habit of 62 patients before and after taking bran.

thing of the past and only 11 had to exert themselves when emptying their bowels. Some stated that they now emptied their bowels completely, whereas formerly this was not the case. Sixty said that their stools were softer, and two who previously had bouts of diarrhoea reported that their motions had become formed and soft.

\section{RELIEF OF SYMPTOMS}

Patients with diverticular disease may complain of more than one symptom, and the main presenting symptoms in the 70 patients are recorded in Table II. Altogether there were 171 symptoms; $14(8.2 \%)$ were experienced by the eight patients who did not take the bran diet. Of the remaining 157 presenting symptoms only $6(3.8 \%)$ were not relieved. Sixty-two $(39.5 \%)$ were relieved by the diet and the patients continued taking bran without supervision. The remaining $89(56.7 \%)$ presenting symptoms disappeared once the bran diet had taken effect.

Thus a change to the bran diet relieved or abolished the symptoms of diverticular disease in $88.6 \%$ of the patients. Frequent small motions or episodes of diarrhoea, sometimes the result of using laxatives, were the main problem of seven patients. All were improved. One who defecated 12 times a day and another who did so six times a day passed motions but twice a day on the bran diet. A further patient who passed motions

TABLE II-Presenting Symptoms

\begin{tabular}{|c|c|c|c|c|c|c|}
\hline & & \multirow{2}{*}{$\begin{array}{c}\text { Before } \\
\text { Bran }\end{array}$} & \multirow{2}{*}{$\begin{array}{l}\text { Bran } \\
\text { Not } \\
\text { Toler- } \\
\text { ated }\end{array}$} & \multicolumn{3}{|c|}{$\begin{array}{l}\text { Symptoms After } \\
\text { Bran: }\end{array}$} \\
\hline & & & & $\begin{array}{c}\text { Not } \\
\text { Re- } \\
\text { lieved }\end{array}$ & $\begin{array}{c}\mathrm{Re}- \\
\text { lieved }\end{array}$ & $\begin{array}{l}\text { Abol- } \\
\text { ished }\end{array}$ \\
\hline $\begin{array}{l}\text { Dyspeptic } \\
\text { symptoms }\end{array}$ & $\begin{array}{l}\text { Nausea } \\
\text { Heartburn } \\
\text { Flatulence } \\
\text { Distension } \\
\text { Wind } \\
\end{array}$ & $\begin{array}{r}11 \\
2 \\
2 \\
36 \\
13\end{array}$ & $\frac{1}{4}$ & $\begin{array}{l}\frac{1}{1} \\
\frac{2}{-}\end{array}$ & $\begin{array}{r}2 \\
2 \\
1 \\
14 \\
4\end{array}$ & $\frac{7}{16}$ \\
\hline $\begin{array}{l}\text { Painful diverticular } \\
\text { disease }\end{array}$ & $\begin{array}{l}\text { Right iliac fossa, pain } \\
\text { or ache } \\
\text { Left iliac fossa, pain } \\
\text { or ache } \\
\text { Lower or general } \\
\text { abdominal pain } \\
\text { Severe colic }\end{array}$ & $\begin{array}{r}7 \\
22 \\
28 \\
12\end{array}$ & $\begin{array}{l}- \\
1 \\
3 \\
1\end{array}$ & $\begin{array}{l}- \\
1 \\
=\end{array}$ & $\begin{array}{r}5 \\
7 \\
11 \\
4\end{array}$ & $\begin{array}{r}2 \\
13 \\
14 \\
7\end{array}$ \\
\hline Bowel symptoms & $\begin{array}{l}\text { Tender rectum } \\
\text { Incomplete emptying } \\
\text { of rectum } \\
\text { Constipation }\end{array}$ & $\begin{array}{r}4 \\
6 \\
28\end{array}$ & - & - & $\begin{array}{l}1 \\
2 \\
8\end{array}$ & $\begin{array}{r}3 \\
3 \\
15\end{array}$ \\
\hline Total $\quad \ldots$ & .. & 171 & 14 & 6 & 62 & 89 \\
\hline
\end{tabular}


three times a day on bran preferred this to episodic diarrhoea and abdominal discomfort.

\section{REPLACEMENT OF LAXATIVES}

Altogether 49 of the 70 patients took laxatives when first seen; 27 bought them at their own expense while 22 obtained them from their doctor. Of the 62 who took unprocessed bran only seven needed laxatives as well; two took senna fruit (Senokot) occasionally, four took sterculia regularly or occasionally, and two preferred psyllium (I-so-gel). Some of these seven patients occasionally took salts.

\section{DIETARY CHANGES}

Most patients were prepared to alter their diet besides taking unprocessed bran once the reason for this change had been explained to them. Forty-nine changed to wholemeal bread and ate All-Bran and Weetabix, and 14 took porridge. The bran diet did not change the appetite of 35 patients whose appetite was good but improved it in 26 whose appetite was poor. The appetite of one was poor after partial gastrectomy and this was unchanged. In not one of the 62 patients was the appetite made worse by bran. This suggests that the widely held view that so-called "roughage" irritates the gut is not founded on fact; bran when moist becomes "softage."

\section{EPISODES OF DIVERTICULITIS}

Two patients had "acute diverticulitis" before taking bran, but as they both had a normal white cell count and sedimentation rate they should be classified as having "painful diverticular disease" (Painter, 1968). A third had three attacks of "left renal colic" which proved to be colonic in origin (see below). All three remained well on the bran diet. On the other hand, this regimen does not prevent attacks of painful diverticular disease or acute diverticulitis. Three of the 62 patients whose symptoms were relieved by bran were later admitted to hospital with pain and tenderness in the left iliac fossa. Only one of them had acute suppurative diverticulitis and all three recovered with conservative treatment.

Twelve patients who suffered from painful diverticular disease had recurrent attacks of severe colic and might well have come to surgery (Table II). One of them did not like bran but was made comfortable with sterculia, while in four the colic was relieved and in seven it was abolished by the bran diet. None came to surgery despite the fact that formerly they had had attacks of severe pain. One woman of 50 had had three attacks of left renal colic which required pethidine. When the correct diagnosis of diverticular disease was made she was placed on the bran diet and had no further pain for two years. Occasionally she experienced mild cramp in the left iliac fossa which was in the same position as her former severe colic. This disappeared when she doubled her intake of bran for a few days. Thus even severe pain which might have led to surgery will respond to a high-residue diet.

\section{DISEASES ASSOCIATED WITH DIVERTICULOSIS}

All 70 patients had at least one barium-enema examination and one sigmoidoscopy. Thirty-five had barium-meal examinations, some of which were followed through the gut, 14 had cholecystograms, and six had intravenous pyelograms. These and other investigations showed that only $11(15 \cdot 7 \%)$ patients were free of other disease. Other diseases found are listed in Table III; 19 patients had two additional diseases, while one woman of 64 had a hiatus hernia, duodenal ulcer, diverticulosis, and had already lost her appendix and gall bladder. She had taken
TABLE III-Other Diseases Found in 70 Patients with Diverticula

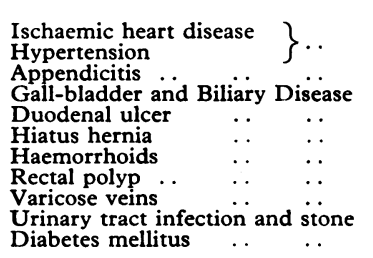

No. of Patients

Ischaemic heart disease

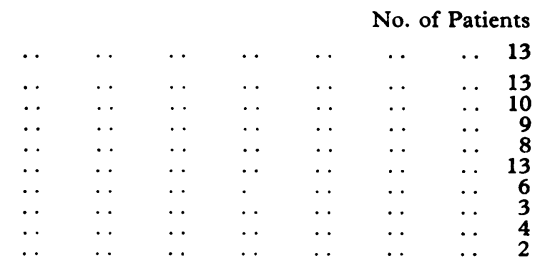

cathartics before being given unprocessed bran and at the time of writing was taking 2 tablespoons of it daily; apart from occasional heartburn, she remained symptom-free for 33 months.

\section{Discussion}

This study shows that provided no changes due to inflammation have caused organic stenosis in the colon the symptoms of diverticular disease are relieved by a high-residue diet. The ideal high-residue diet is expensive and difficult to obtain, but unprocessed bran is a cheap substitute for the cellulose fibre missing from the modern diet. The cheapness of bran is important to those of limited means. The use of conventional laxatives is not without risk (Painter, 1971). Paraffin and the hydrophilic colloids have disadvantages, and the prolonged use of senna destroys the colon's intrinsic nerve supply (Smith, 1968). Thus it is not only more natural but safer to treat diverticular disease by diet rather than drugs. Furthermore, its widespread use would save money.

The relative effects of fibre depletion in cereal refining and the indirect effect of sugar refining are as yet unknown. Since 1880 the refining of flour by roller milling and an increasing consumption of refined sugar has led to a steady reduction in the fibre content of the diet (Fig. 1). Modern Western man eats white flour of $70 \%$ extraction, and so he ingests less than $0.1 \mathrm{~g}$ of cereal fibre daily (H. C. Trowell, personal communication, 1971). We advised the present patients to replace the missing fibre and to reduce their consumption of refined sugar. British experience in the second world war also suggests that a return to a high-residue, low-sugar diet would improve the prognosis in diverticular disease (Cleave, Campbell, and Painter, 1969; Painter and Burkitt, 1971). Most of the diseases that were associated with diverticulosis in these patients were diseases which have become common in Western nations in this century, and our findings are consistent with the idea that they all have a dietary cause.

The beneficial effects of bran on the symptoms of diverticular disease are not only of practical importance but are also of theoretical interest. The symptoms of diverticular disease can be grouped, in descending order of magnitude, into those associated with (1) acute diverticulitis-the symptoms of which vary according to the damage that is wrought by the inflammatory process; (2) painful diverticular disease-the colic of this condition waxes and wanes too rapidly to be due to inflammation and is now attributed to functional obstruction brought about by excessive colonic segmentation (Painter, 1968); and (3) diverticulosis-colonic diverticula may be associated with vague symptoms such as a sense of fullness, flatulence, abdominal distension and aching, a loss of appetite, and alterations in the bowel habit.

The symptoms of diverticulosis cannot be due to the presence of diverticula alone as both a high-residue diet and Reilly's operation will relieve symptoms without removing them. Hence the place of origin of these symptoms is uncertain but their relief by the bran diet may throw some light on their cause. If a fibre-deficient diet can damage the colon to an extent sufficient to produce diverticula is it not unlikely that this is the only part of the intestinal tract to be adversely affected by our modern diet? Is it not possible, therefore, that the symptoms 
of diverticulosis originate in other parts of the gut which also have not adapted to a low-residue diet and whose motility is altered by this diet?

The concept that the whole of the alimentary tract has to struggle with a low-residue diet explains not only why "upper intestinal" symptoms accompany diverticulosis but also how the bran diet relieves symptoms which appear to arise at different levels of the gastrointestinal tract.

It is a pleasure to thank Surgeon Captain Cleave for his advice on the use of unprocessed bran, and Mr. Denis Burkitt, Sir Richard Doll, and Sir Clifford Naunton-Morgan for their helpful advice. We are indebted to the records department of Manor House Hospital and to my secretary, Miss Joan Inglis, for their assistance. Messrs. Allinsons donated the bran, and advised us of its composition.

ADDENDUM.-Since this follow-up was completed in March
1971 we know of no patients who relapsed on this diet. One died from other causes.

\section{References}

Cleave, T. L. (1941). British Medical fournal, 1, 461

Cleave, T. L., Campbell, G. D., and Painter, N. S. (1969). Diabetes, Coronary Thrombosis and the Saccharine Disease. Bristol, Wright.

Cowgill, G. R., and Anderson, W. E. (1932). Fournal of the American Medical Association, 98, 1866 .

Dimock, E. M. (1936). The Treatment of Habitual Constipation by the Bran Method. University of Cambridge, M.D. Thesis.

Painter, N. S. (1964). Annals of the Royal College of Surgeons of England, 34, 98.

Painter, N. S. (1968). British Medical fournal, 3, 475.

Painter, N. S. (1970). Proceedings of the Royal Society of Medicine, 63, Suppl., p. 144.

Painter, N. S. (1971). Lancet, 2, 381.

Painter, N. S., and Burkitt, D. P. (1971). British Medical fournal, 2, 450. Smith, B. (1968). Gut, 9, 139.

\section{PRELIMINARY COMMUNICATIONS}

\section{Unbalanced Deoxyribonucleotide Synthesis Caused by Methotrexate}

\author{
A. V. HOFFBRAND, EDITH TRIPP
}

British Medical fournal, 1972, 2, 140-142

\section{Summary}

The effect of methotrexate on the free intracellular pools of thymidylate triphosphate (dTTP) and deoxyadenosine triphosphate (dATP) in normal human phytohaemagglutinin-transformed lymphocytes has been studied. Methotrexate caused a fall in the dTTP pool ranging from $\mathbf{3 8} \%$ to $\mathbf{8 8} \%$ and a rise in the dATP pool ranging from $24 \%$ to $185 \%$.

A rise in the free intracellular pool of dATP is thought to inhibit both rubonucleotide reduction and polynucleotide ligase, an enzyme concerned in DNA synthesis and repair. The hypothesis is suggested here that folate deficiency per se, as well as a functional folate deficiency induced by methotrexate may cause reduced DNA synthesis, megaloblastic changes, and chromosome abnormalities by producing a rise in the free intracellular pool of dATP as well as by causing a fall in free intracellular dTTP.

\section{Introduction}

It is now well accepted that megaloblastic anaemia arises because of a disturbance in DNA synthesis in haemopoietic cells. Folate deficiency is thought to cause this anaemia by reducing synthesis of thymidylate triphosphate (dTTP) (one of the two pyrimidine nucleotides incorporated into DNA), since a folate coenzyme, 5,10-methylenetetrahydrofolate, is needed for synthesis of thymidylate from its immediate precursor deoxyuridylate (Wahba and Friedkin, 1962; Metz et al., 1968; Das and Hoffbrand, 1970) (see Fig.). Vitamin $B_{12}$ is not required directly

\footnotetext{
Department of Haematology, Royal Postgraduate Medical School London W12

A. V. HOFFBRAND, B.M., B.CH., M.R.C.P., Lecture

EDITH TRIPP, B.SC., Scientific Officer
}

for the reaction but its deficiency is thought indirectly to cause depletion of the folate coenzyme involved in thymidylate synthesis and thus secondarily to reduce synthesis of dTTP (Herbert and Zalusky, 1962; Waters and Mollin, 1963). The base composition of the DNA formed in megaloblastic anaemia is normal (Hoffbrand and Pegg, 1972) but it is still not clear, however, whether lack of thymidylate alone is the cause of the abnormal morphological and chromosomal appearance seen in megaloblastic anaemia.

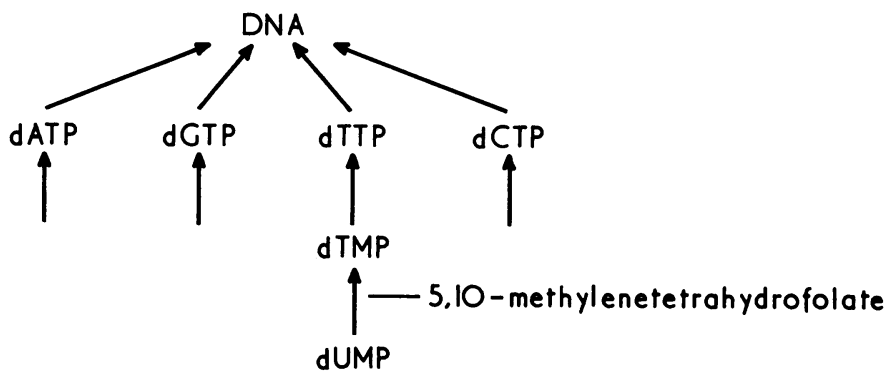

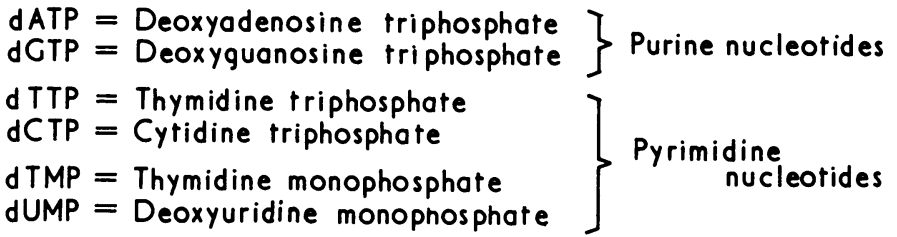

Normal synthesis of DNA from purine and pyrimidine nucleotides.

The purpose of the present communication is to report a second disturbance in nucleotide synthesis that may be brought about by folate deficiency in human haemopoietic cells and which may be relevant to the disturbance in DNA synthesis that occurs in megaloblastic anaemia and in patients receiving the folate antagonist methotrexate-namely, a rise in the intracellular pool of one of the two purine nucleotides incorporated into DNA, deoxyadenosine triphosphate (dATP) (see Fig.). An increased intracellular level of this compound has been shown to cause a number of disturbances of the synthesis of DNA and its precursors in bacteria and other mammalian cells, and we suggest here that a rise in the intracellular pool of dATP as well as a fall in the intracellular pool of dTTP may be responsible for the effect of folate deficiency on proliferating (DNAsynthesizing) cells. In these experiments methotrexate, a folate antagonist, was used to produce folate deficiency in 